\title{
PLANEJAMENTO FINANCEIRO PESSOAL: UMA FERRAMENTA NA COMPLEMENTAÇÃO DA RENDA PREVIDENCIÁRIA BRASILEIRA
}

\section{ARTIGO ORIGINAL}

SILVA, Lucílio Damião da ${ }^{1}$

FRANÇA, Eveline Gomes de Oliveira ${ }^{2}$

RODRIGUES, Gelson Modesto ${ }^{3}$

BINOTI, Alex da Conceição ${ }^{4}$

AZEVEDO, Fernanda Aparecida Bregues de ${ }^{5}$

SILVA, Lucílio Damião da. Et al. Planejamento financeiro pessoal: Uma ferramenta na complementação da renda Previdenciária brasileira. Revista Científica Multidisciplinar Núcleo do Conhecimento. Ano 05, Ed. 10, Vol. 07, pp. 138-153. Outubro de 2020. ISSN: 2448-0959, Link de acesso: https://www.nucleodoconhecimento.com.br/contabilidade/planejamentofinanceiro

1 Pós-Graduado em Especialização em Finanças pela Universidade Federal Fluminense - UFF, Instituto de Matemática e Estatística.

2 Pós-Graduada em Especialização em Finanças pela Universidade Federal Fluminense - UFF, Instituto de Matemática e Estatística.

3 Pós-Graduado em Especialização em Finanças pela Universidade Federal Fluminense - UFF, Instituto de Matemática e Estatística.

4 Pós-Graduado em Especialização em Finanças pela Universidade Federal Fluminense - UFF, Instituto de Matemática e Estatística.

5 Pós-Graduada em Especialização em Finanças pela Universidade Federal Fluminense - UFF, Instituto de Matemática e Estatística. 


\section{RESUMO}

A Previdência Social brasileira tem suas origens no Brasil imperial, evoluindo ao longo dos anos, passando por mudanças frutos de demandas sociais que almejam por uma renda previdenciária capaz de suprir suas necessidades pessoais ao se passar da idade ativa para a inatividade. A nova Reforma da Previdência, ocorrida em 2019, trouxe mudanças significativas nos fatores previdenciários que impactaram no valor do benefício concedido pelo governo aos segurados, fomentando, assim, à problemática da necessidade de complementação de renda para suprir a perda salarial advinda da Previdência Social na fase da inatividade. O objetivo deste trabalho é traçar um planejamento financeiro pessoal capaz de simular a complementação de renda de um segurado com base no teto definido pela Previdência Social brasileira, capaz de suprir a perda salarial advinda da aposentadoria. Para se atingir esse objetivo, utilizou-se das metodologias de pesquisa documental e bibliográfica, de dados coletados de bases científicas e órgãos governamentais e que fomentaram um Planejamento Financeiro pessoal hipotético, cuja análise dos resultados comprovaram que é possível suprir a perda salarial advinda da aposentadoria através de um planejamento.

Palavras-chaves: Previdência Social, Previdência Complementar, Planejamento Financeiro Pessoal, Aposentadoria.

\section{INTRODUÇÃO}

A temática sobre a Previdência Social brasileira voltou a ter destaque com a aprovação de sua Reforma em 2019 (BRASIL, 2019). Ao se abordar esse tema, fazse necessário evidenciar parte da sua evolução histórica com suas origens no Brasil imperial, de acordo com o Quadro abaixo: 
Quadro 1 - Linha do Tempo - Evolução Histórica da Previdência Social brasileira

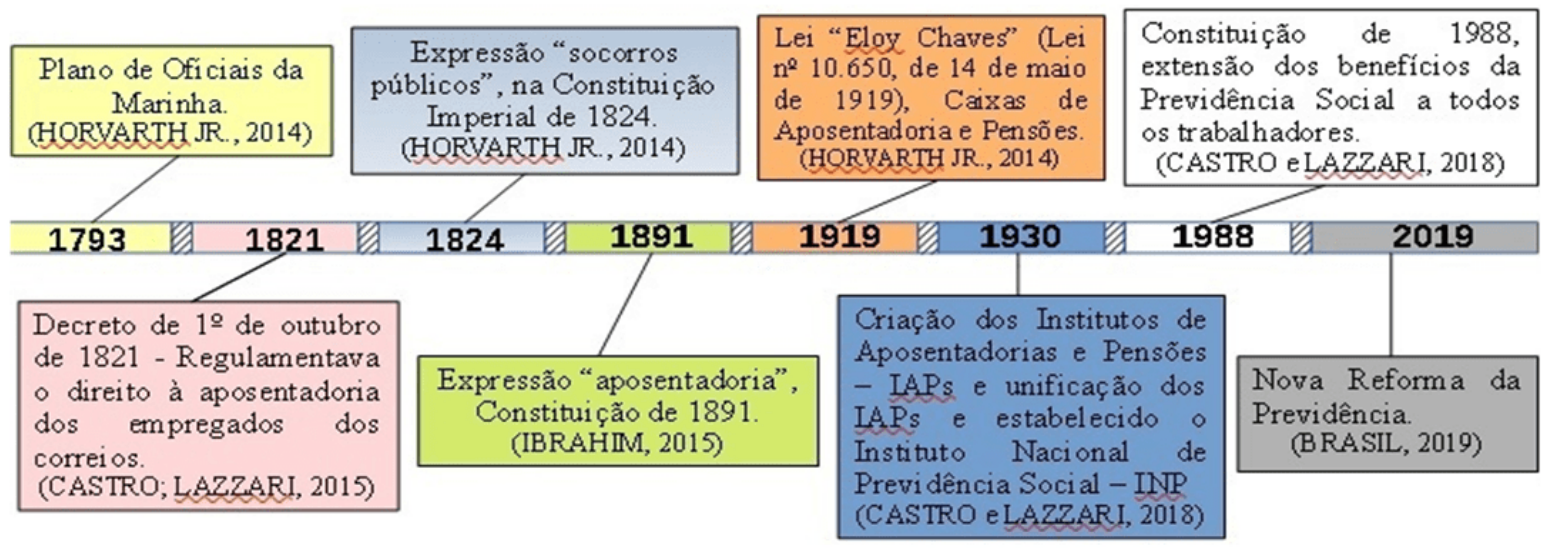

Fonte: Silva (2020).

A Nova Previdência passou a vigorar em novembro de 2019, com a promulgação da Emenda Constitucional (EC) № 103, abrangendo novas regras para segurados do Regime Próprio de Previdência Social (RPPS) da União e do Regime Geral de Previdência Social (RGPS) (PORTAL DA PREVIDÊNCIA, 2019). As alterações nos requisitos previdenciários abrangeram fatores como: aumento no tempo de contribuição; alteração na idade limite para homens e mulheres; regras de transição; mudança no fator de cálculo do valor do benefício; fixação do teto limite; alteração no percentual da média salarial (BRASIL, 2019).

A aprovação da Nova Previdência desencadeou a problemática sobre a necessidade de complementação de renda na fase da aposentadoria. Para Madureira, Méxas e Drumond (2017), o rendimento baseado na aposentadoria oficial não é suficiente para que o trabalhador brasileiro possa compensar a perda salarial sofrida ao se passar para a inatividade. É necessário que os contribuintes, ainda na fase ativa, pesquisem por alternativas de investimento e/ou acumulação de renda disponíveis no mercado financeiro, utilizando como ferramenta um Planejamento Financeiro pessoal.

O presente trabalho tem como objetivo traçar um Planejamento Financeiro pessoal capaz de simular a complementação de renda de um segurado com base nos novos requisitos previdenciários que seja capaz de suprir a perda salarial advinda da aposentadoria, além de contribuir para a divulgação da importância de se utilizar o 
Planejamento Financeiro pessoal como ferramenta para complementação e/ou acúmulo de renda. Para se atingir esse objetivo, utilizou-se das metodologias de pesquisa documental e bibliográfica, e a análise e coleta de dados foi realizada por meio da verificação dos resultados obtidos de uma simulação hipotética de um Planejamento Financeiro pessoal.

\section{METODOLOGIA}

De acordo com Gil (2008) a pesquisa bibliográfica recorre a utilização de diversas pesquisas e opiniões expressas em documentos com teor científico, como: artigos, livros, trabalhos acadêmicos, bases científicas reconhecidas, que, em certo momento, já abordaram temáticas sobre o objeto de estudo proposto, além de considerar esse tipo de pesquisa vantajosa pela gama de informações sobre o estudo em tela. $O$ autor também compara a pesquisa documental à bibliográfica, por enfatizar dados e informações não trabalhadas anteriormente por nenhuma outra pesquisa.

$\mathrm{Na}$ elaboração deste artigo foram utilizados dados e informações oriundas de artigos científicos, periódicos, livros, trabalhos acadêmicos e fontes governamentais que abordam a temática sobre a Previdência Social brasileira e a problemática da complementação da renda advinda da perda salarial ao se aposentador, considerando os requisitos previdenciários atuais.

Para Fachin (2003), a coleta e análise de dados em uma pesquisa científica utiliza-se de tabelas e gráficos para que os dados possam ser analisados de formas distintas e demonstrados conforme suas variáveis. Para a coleta e análise dos dados desse trabalho foram utilizadas informações advindas de um Planejamento Financeiro pessoal de um caso hipotético, fomentadas a partir de dados obtidos de fontes governamentais e periódicos sobre o mercado financeiro que expressam a realidade de um indivíduo brasileiro que almeja a complementação de renda em virtude da perda salarial ao se passar para a inatividade que atenda às suas expectativas futuras. 


\section{REFERENCIAL TEÓRICO}

\subsection{A PREVIDÊNCIA SOCIAL BRASILEIRA}

A Previdência Social brasileira é o programa público regulado por normas constitucionais que viabiliza o pagamento de aposentadorias aos trabalhadores em época própria. Todavia, o sistema não oferece apenas aposentadorias, pois disponibiliza, também, benefícios como salário-maternidade, auxílio-doença e pensão por morte. A contribuição com o programa é obrigatória, conforme consta nos termos do artigo 201, da Constituição Federal de 1988 (BRASIL, 1988).

Os programas públicos ofertados pelos governos municipais, estaduais e federal para custeio dos servidores públicos é denominado Regime Próprio de Previdência Social. Por outro lado, denomina-se Regime Geral de Previdência Social (RGPS) aquele referente aos servidores públicos não filiados ao regime próprio, controlado pelo Instituto Nacional do Seguro Social - INSS (PORTAL DA PREVIDÊNCIA, 2019).

Assim, o Regime Geral de Previdência Social (RGPS) vincula os servidores não filiados ao regime próprio, bem como todos os trabalhadores do setor privado. $O$ Regime Próprio de Previdência Social está previsto no artigo 40, da Constituição Federal da República de 1988 (BRASIL, 1988).

\subsection{PLANOS DE PREVIDÊNCIA PRIVADA BRASILEIROS}

O Regime de Previdência Complementar - RPC, visa proporcionar ao trabalhador uma proteção previdenciária complementar àquelas oferecidas pelo Sistema de Previdência Estatal (Regime Geral de Previdência Social - RGPS e Regime Próprio de Previdência Social - RPPS), cujas contribuições são obrigatórias. Sua normatização está contida no artigo 202 da Constituição Federal Brasileira de 1988 e ao contrário do Regime Geral e do Regime Próprio de Previdência sua adesão é facultativa por tratar-se de um sistema complementar (BRASIL, 1988). 
O RPC é um sistema completamente autônomo, com gestão desvinculada dos regimes públicos, seus regulamentos estão preconizados nas Leis Complementares № 108 e 109/2001 e seus recursos são provenientes das contribuições acumuladas ao longo do tempo (BRASIL, 2001a; 2001b). O sistema divide-se em Fundos de Previdências Complementares Abertos, cuja adesão é facultada a qualquer pessoa e os Fundo de Previdências Complementares Fechados, cuja adesão é restrita a grupos determinados, ambos com características próprias, inclusive os órgãos governamentais de fiscalização (PREVIC, 2018).

\subsection{ALTERNATIVAS DE INVESTIMENTO E/OU ACUMULAÇÃO DE RENDA}

Para Cerbasi (2014) com o aumento da expectativa de vida da população brasileira nos últimos anos, ficou evidente o risco financeiro futuro ao se depender da Previdência Social concedida pelo Instituto Nacional de Seguridade Social (INSS). Ainda considerando os dados do Departamento Intersindical de Estatística e Estudos Socioeconômicos - Dieese (2019), no País, cerca de 65\% dos benefícios concedidos pelo INSS equivalem a um salário-mínimo, que em 2020 corresponde a $R \$ 1.045,00$, valor aprovado pela Media Provisória oㅡ 919, de 1으 de fevereiro de 2020 (BRASIL, 2020).

Visando manter o patamar financeiro atual capaz de suprir suas necessidades e a qualidade de vida, os contribuintes devem traçar um plano voltado para o seu futuro financeiro, através da busca de alternativas individuais de investimento e/ou acumulação de renda e da elaboração de um Planejamento Financeiro individual. Há no mercado financeiro algumas opções disponíveis, dentre as quais: o Tesouro Direto; a Bolsa de Valores; a Caderneta de Poupança; o Fundo de ações; os CDBs Certificados de Depósitos Bancários; os RDBs - Recibos de Depósitos Bancários, e outros. 


\subsubsection{TESOURO DIRETO}

É um programa do Tesouro Nacional de compra e venda de títulos federais por pessoa física através da internet. Os títulos públicos são ativos de renda fixa emitidos pelo Tesouro Nacional sob forma eletrônica. Se trata de um investimento com rentabilidade e segurança do governo federal e apresenta vantagens de custo e flexibilidade na escolha de títulos públicos (PORTAL TESOURO TRANSPARENTE, 2019).

\subsubsection{BOLSA DE VALORES}

É uma organização de mercado onde se negociam ações de capital aberto (públicas e privadas), onde ocorrem as transações de compra e venda de títulos e valores mobiliários. O objetivo da bolsa é organizar essas negociações em um ambiente seguro garantindo que o vendedor receba o valor pela venda e o investidor receba as ações que comprou de forma segura e justa, também garantindo que as ações sejam guardadas em um ambiente 100\% seguro, a CBLC (TORORADAR, 2016).

\subsubsection{CADERNETA DE POUPANÇA}

A caderneta de poupança é utilizada para armazenar dinheiro. Na poupança o rendimento é calculado mensalmente sobre o dinheiro que está na conta e o valor dos juros é depositado automaticamente na data de aniversário de abertura da conta. A remuneração básica da poupança depende do valor da taxa referencial que é calculada diariamente pelo Banco Central, já a remuneração adicional é feita através da Taxa Selic que é uma taxa de juros da economia no Brasil onde o Banco Central controla a compra e venda de títulos, essa taxa é obtida pelo cálculo da taxa média ponderada dos juros praticados pelas instituições financeiras (INVESTIMENTOS E NOTÍCIAS, 2018).

\subsubsection{FUNDO DE AÇÕES}

O objetivo dos fundos são investir no mercado acionário, deve-se aplicar $67 \%$ no mínimo ou 2/3 do seu patrimônio em ações negociadas no mercado organizado. Os 
fundos de ações são um investimento coletivo onde recursos de vários investidores são aplicados em conjunto no mercado acionário e os ganhos são divididos entre os participantes na proporção do valor investido de cada um. Esses investimentos são negociados na bolsa de valores e seu rendimento acompanha o desempenho diário, uma característica dos fundos de ações é a volatilidade, ou seja, as variações podem ocorrer de maneira brusca (INFOMONEY, 2020).

\subsubsection{CDBS - CERTIFICADOS DE DEPÓSITOS BANCÁRIOS}

Os investimentos são feitos através de bancos, são investimentos de renda fixa onde se investe dinheiro por um determinado período, e em troca se obtém os juros. No mercado possuem os seguintes tipos de CDBs: Prefixados, onde o investidor consegue calcular exatamente quanto receberão com o vencimento do papel. CDBs pós-fixado, nesse tipo o investidor não consegue ter certeza do qual será o valor do seu retorno pois ele seguirá as variações do indicador. CDBs atrelados à inflação, onde mescla as duas opções anteriores oferecendo uma remuneração prefixada e outra pós fixada (INFOMONEY, 2020).

\subsubsection{RDBS - RECIBOS DE DEPÓSITOS BANCÁRIOS}

Os investimentos são feitos através de bancos, cooperativas e corretoras, são investimentos de renda fixa onde se investe dinheiro por determinado período, e em troca se obtém juros. No mercado possuem os seguintes tipos de RDBs: Prefixados, onde o investidor consegue calcular exatamente quanto receberão com o vencimento do papel. RDBs pós-fixado, nesse tipo o investidor não consegue ter certeza do qual será o valor do seu retorno pois ele seguirá as variações do indicador. RDBs atrelados à inflação, onde mescla as duas opções anteriores oferecendo uma remuneração prefixada e outra pós fixada.

As principais diferenças entre CDBs e RDBs são os tipos de instituições onde investirão e o retorno em relação a liquidez já que os RDBs não têm seu resgate antes do vencimento e nos CDBs é permitido resgate antes do tempo, isso é, pode ser resgatado a qualquer momento (INFOMONEY, 2020). 


\subsection{PLANEJAMENTO FINANCEIRO PESSOAL}

O Planejamento Financeiro Pessoal é essencial para que o indivíduo possa ter a real noção de como está alicerçada sua vida financeira, além de mensurar se os objetivos almejados estão de acordo com sua renda. Independentemente da faixa de renda, um plano financeiro permite haver uma visão clara do patrimônio, amplia as chances de lidar com contratempos financeiros e com as grandes mudanças na vida, além de evitar problemas de endividamento e crédito e orientar na decisão de onde investir a reserva financeira. (COMISSÃO DE VALORES IMOBILIÁRIOS, 2019).

Para que o Planejamento Financeiro seja elaborado é necessário que o indivíduo estabeleça objetivos claros e mensuráveis financeiramente. Para Gitman (2010, p.107) "o primeiro passo do planejamento financeiro pessoal é definir suas metas. Enquanto uma empresa objetiva maximizar a riqueza dos acionistas (ou seja, o preço da ação), as pessoas normalmente têm diversos objetivos importantes". Ainda para o autor, as metas podem ser de curto prazo, médio prazo ou longo prazo. As metas de curto (prazo menor) e médios prazos (intermediárias) sustentam as de longo prazo (prazo extenso).

Com os objetivos e metas pessoais estabelecidos, há a coleta de todas as informações relevantes, elencando-se todas as fontes de receitas e todos os gastos e despesas, que acarretam a formação do Orçamento Pessoal. Com as informações consolidadas no Orçamento Pessoal, passa-se para a fase das análises e provisões necessárias para que as metas estabelecidas sejam alcançadas, ou seja, são tomadas as decisões de investimentos (GARCIA e KLOECKNER, 2005).

\section{RENDA ALMEJADA NA FASE DA APOSENTADORIA}

A publicação da EC nํㅗ 103, a Nova Previdência Social, no Diário Oficial da União (DOU), em 13 de novembro de 2019, passou a vigorar em todo o território nacional e trouxe a tona a preocupação dos brasileiros com o futuro financeiro mediante as alterações previdenciárias aprovadas. A nova emenda ao documento constitucional 
trouxe novos fatores previdenciários como requisitos aos segurados para concessão do benefício oficial fornecido pelo governo (BRASIL, 2019).

O Planejamento Financeiro pessoal, diante dessa mudança, tornou-se necessário. Com base nessa assertiva, na pesquisa no mercado financeiro e na escolha da alternativa ideal para acumulação de renda, visando complementar a renda obtida pela aposentadoria, deve-se alinhar aos objetivos traçados pelo indivíduo ainda na fase ativa da vida. Considera-se fatores como: tempo de investimento (curto, médio e longo); tipo de investimento; variações de mercado; além daqueles que impactam diretamente no orçamento, como despesas fixas: moradia, alimentação, serviços (água, luz, internet), e despesas variáveis: educação, plano de saúde, vestuário, lazer, dentre outros (PORTAL DA PREVIDÊNCIA, 2019).

\subsection{O CASO HIPOTÉTICO}

O Sr. Marcelo Figueiredo Xavier (nome fictício) pretende se aposentar após cumprir os requisitos previdenciários vigentes e ter uma renda mensal futura equivalente ao seu salário atual de $R \$ 6.800,00$, considerando, no entanto, apenas a remuneração que será fornecida pela Previdência Social brasileira, respeitando-se o teto atual estabelecido pela EC no 103, cujo valor equivale a $R \$ 4.880,85$ (BRASIL, 2019).

Para Madureira, Méxas e Drumond (2017), isso não seria possível, razão pela qual opta-se pela realização de um Planejamento Financeiro pessoal como estratégia para acumulação de renda. Deve-se considerar, ainda, a idade limite para aposentadoria oficial, que para homens é de 65 anos (BRASIL, 2019).

Para que o Planejamento Financeiro do Sr. Marcelo seja realizado e torne-se eficaz, é necessário que seja observado o seu "orçamento anual", elencando-se as variáveis que possam comprometer o valor destinado ao investimento e/ou acumulação de renda. 


\section{ANÁLISE DOS RESULTADOS}

A Tabela 1 demonstra como as receitas e despesas do Sr. Marcelo estão organizadas financeiramente.

Tabela 1 - Orçamento Anual

\begin{tabular}{|c|c|c|c|}
\hline \multicolumn{2}{|c|}{ Receitas Anuais } & \multicolumn{2}{|l|}{ Despesas Anuais } \\
\hline Salário & $90.666,67$ & Moradia & $12.000,00$ \\
\hline & & Serviços (água, luz, tel..) & $6.000,00$ \\
\hline & & Alimentação & $9.600,00$ \\
\hline & & Vestuário & $6.000,00$ \\
\hline & & Transporte & $12.000,00$ \\
\hline & & Despesas médicas & $12.000,00$ \\
\hline & & Educação & $7.200,00$ \\
\hline & & Outros (taxas, lazer, manut.) & $9.687,37$ \\
\hline & & Previdência Privada & $3.600,00$ \\
\hline & & Investimentos & $3.600,00$ \\
\hline & & Despesas Totais sem Impostos & $81.687,37$ \\
\hline & & Impostos $(27,5 \%)$ & $8.979,30$ \\
\hline Receitas Totais & $90.666,67$ & Despesas Totais & $90.666,67$ \\
\hline
\end{tabular}

Fonte: França (2020).

Considerando os dados deste trabalho definidos como marco 0 (zero) para a elaboração do Planejamento da Aposentadoria do Sr. Marcelo (caso hipotético), tanto em relação à contribuição para a Previdência Social, quanto para os aportes em Previdência Privada e em Investimentos Individuais, obtêm-se:

- Tempo estimado para a aposentadoria: 30 anos;

- Valor da Aposentadoria pela Previdência Social: $\mathrm{R} \$ 4.880,85$;

- Renda almejada para complementar a aposentadoria: $R \$ 1.919,15$;

- Tempo estimado para usufruir da renda: 20 anos.

Para o cálculo do valor a ser recebido de aposentadoria pela Previdência Social, considerou-se a contribuição para o teto máximo, $\mathrm{R} \$ 6.101,06$ (BRASIL, 2019). De acordo com a regra em vigor, aos 65 anos de idade um homem com 30 anos de contribuição será aposentado recebendo $80 \%$ de sua média salarial, ou seja, $R \$$ 
4.880,85 (BRASIL, 2019). No caso do Sr. Marcelo, a renda por ele almejada que complementará a sua aposentadoria $(R \$ 1.919,15)$ é a diferença entre o seu salário atual, no valor de $R \$ 6.800,00$, e o valor da aposentadoria prevista, $R \$ 4.880,85$.

Utilizando-se dos cálculos de matemática financeira é possível calcular o montante de reservas necessárias no momento da aposentadoria para se usufruir de determinada renda por um período estipulado, assim como quais são os aportes mensais necessários para se acumular este montante.

Gráfico 1 - Reserva Acumulada - Período a Usufruir

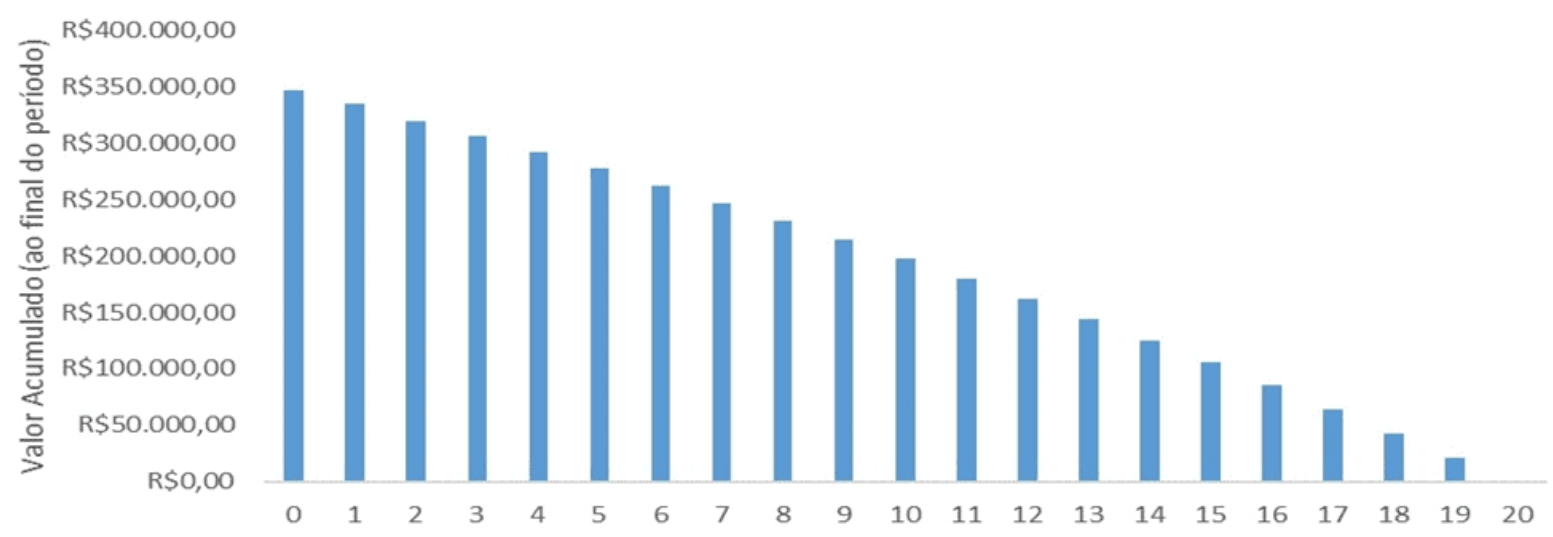

Fonte: França (2020).

O Gráfico 1 demonstra o montante de $\mathrm{R} \$ 347.311,23$ como reservas necessárias na data da aposentadoria, a valores de hoje, para que haja uma renda mensal complementar de $\mathrm{R} \$ 1.919,15$ durante 20 anos, ou 240 meses. Foi considerada uma taxa de juros real de $3 \%$ ao ano, ou $0,2466 \%$ ao mês. 
Gráfico 2 - Reserva Acumulada - Período de Acumulação

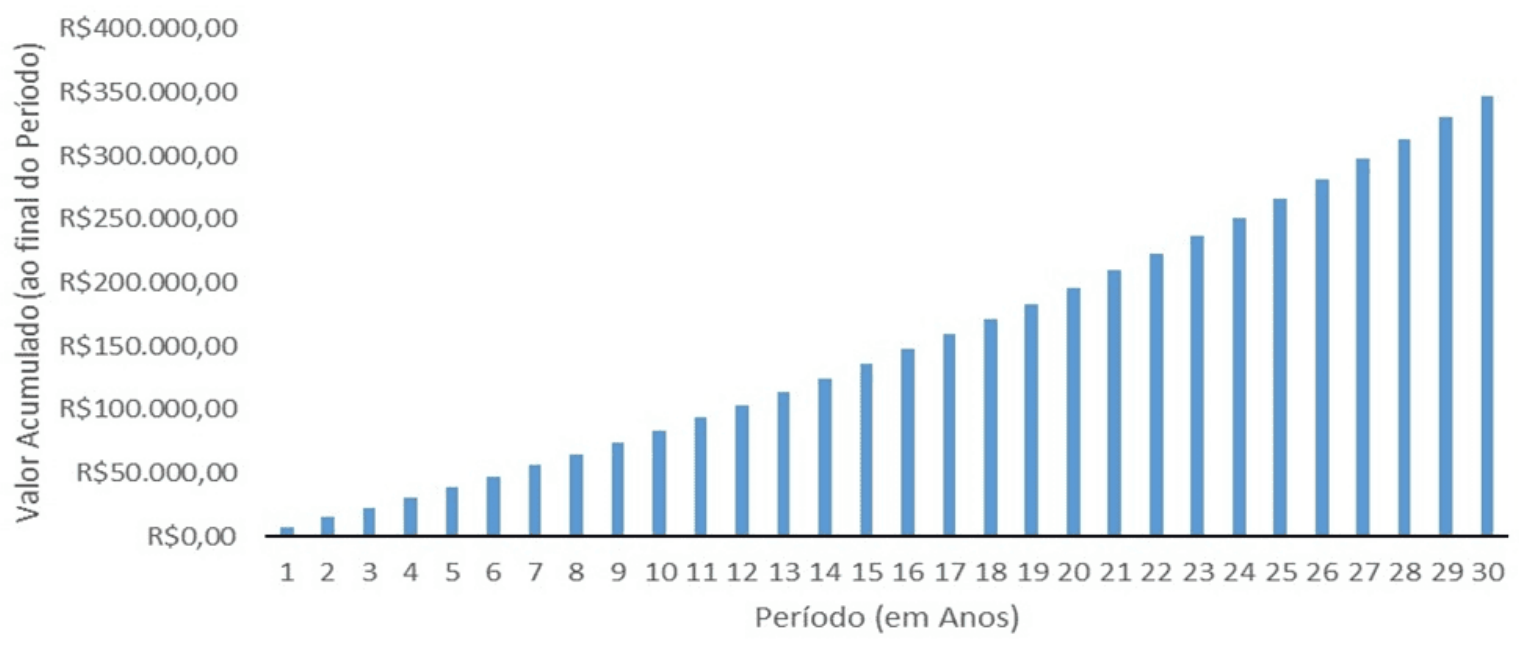

Fonte: França (2020).

O Gráfico 2 representa o Valor Acumulado (VA), em anos, durante o período de acumulação. Para que se consiga acumular $\mathrm{R} \$ 347.311,23$ ao final de 30 anos, ou 360 meses, considerando, conservadoramente, uma taxa real de juros de $3 \%$ ao ano, ou $0,2466 \%$ ao mês, são necessários aportes mensais de $R \$ 600,14$. Tais aportes serão divididos em Previdência Privada e em Investimentos Individuais, uma vez que a parcela alocada em Investimentos Individuais, a depender do investimento escolhido, tem uma liquidez maior que o Plano de Previdência, podendo, assim, ser realocado em investimentos com maiores retornos.

\section{DISCUSSÕES SOBRE A ANÁLISE DOS DADOS}

Os requisitos previdenciários atuais e seus impactos diretos na renda dos segurados ao se passar para a inatividade acarretam a necessidade de se complementar essa renda, pois como consequência da mudança dos fatores previdenciários adveio a "perda salarial". Na regra anterior eram necessários para um homem se aposentar ter a idade limite de 65 anos e tempo de contribuição junto ao INSS de 15 anos, já na regra atual são necessários 65 anos e 20 anos de contribuição, além disso cabe considerar o valor do percentual sobre o teto salarial que pela regra anterior era de $60 \%$ e pela atual de $80 \%$. 
Se considerarmos a renda utilizada no caso do Sr. Marcelo, que tem a idade de 35 anos, $R \$ 6.800,00$, e compararmos com a renda que ele obterá da Previdência Social após cumprir os requisitos previdenciários, $R \$ 4.880,85$, a diferença salarial (perda salarial) que o Sr. Marcelo sofrerá será de $\mathrm{R} \$ 1.919,15$ ao mês. Este é o valor mensal necessário para complementar sua renda previdenciária, que pode ser obtida através da acumulação de renda, por meio da escolha de uma das alternativas disponíveis no mercado financeiro e de um Planejamento Financeiro pessoal.

Para que o Planejamento Financeiro do Sr. Marcelo seja realmente eficaz, ele terá de considerar o seu orçamento atual, os fatores que podem influenciar no seu rendimento, tanto as despesas quanto as receitas, os riscos externos oriundos do mercado financeiro aos quais estará exposto e o fator do tempo por se tratar de acumulação de renda no longo prazo, além das taxas pactuadas. Todas essas variáveis devem ser consideradas, pois, como demonstra o resultado obtido com base no caso hipotético, através de aportes mensais e sucessivos, é possível se obter a complementação de renda almejada para repor a perda salarial ao se passar para a inatividade.

O presente estudo se baseou apenas no caso hipotético do Sr. Marcelo, homem, 35 anos, renda mensal de $\mathrm{R} \$ 6.800,00$, tempo de contribuição faltante 20 anos, classe média, sendo esses fatores limitantes do campo de pesquisa. $\mathrm{Na}$ elaboração do Planejamento Financeiro dele foram considerados a remuneração mensal, como receita, as despesas fixas e eventuais, como despesas, comuns a quaisquer indivíduos, sendo essas adaptáveis para a realidade dos segurados e que podem ser utilizados como referência na elaboração de um Planejamento Financeiro capaz de suprir os objetivos almejados, principalmente o da complementação de renda pela perda salaria advinda da renda do governo.

\section{CONSIDERAÇÕES FINAIS}

A Previdência Social brasileira, após a aprovação de sua Reforma em novembro de 2019, voltou a ser destaque nas mídias sociais e no mercado financeiro brasileiro, impulsionando a problemática sobre a necessidade de complementação de renda na 
fase da inatividade, ao se considerar a renda atual e a futura de cada indivíduo e o teto limite da previdência oficial em vigor.

Os novos fatores previdenciários impactaram diretamente na vida dos contribuintes, fazendo com que a possibilidade de investimentos ou retenção financeira, visando a acumulação de renda como alternativa de complementação de renda para a aposentadoria se tornasse uma necessidade. Antes de se investir, é necessário conhecer as alternativas disponíveis no mercado que sejam capazes de atender as necessidades e objetivos traçados.

Quando se estabelece um Planejamento Financeiro pessoal deve-se considerar fatores que influenciam diretamente no nível de renda desejado, como as despesas fixas que impactam no orçamento individual e que influenciam no valor destinado a se investir. Quanto à escolha do investimento, deve-se considerar o tempo de duração do investimento, o valor futuro a se obter, a taxa real de juros e se o tipo de investimento escolhido é capaz de suprir a renda almejada.

Com base na abordagem elaborada pelo presente estudo, considerando o levantamento teórico e a aplicação hipotética de um planejamento financeiro pessoal para a aposentadoria, foi constatado que é possível traçar um planejamento capaz de suprir a perda salarial da previdência oficial atual e a expectativa de renda futura ao se passar para a inatividade, bastando, no entanto, que haja conhecimento necessário sobre as opções de investimento disponíveis no mercado e/ou o meio de acumulação de renda ideal que satisfaça as necessidades de cada indivíduo.

Esse estudo visa contribuir com a divulgação da temática sobre a previdência social brasileira, da necessidade de se ter uma complementação de renda para suprir as necessidades individuais ao se passar para a inatividade.

\section{REFERÊNCIAS}

BRASIL. [Constituição (1988)]. Constituição da República Federativa do Brasil. Brasília, DF: Senado Federal, 1988. 
BRASIL. [Constituição (1988)]. Emenda Constitucional no 103, de 12 de novembro de 2019. Altera o sistema de previdência social e estabelece regras de transição e disposições transitórias.

BRASIL. Lei Complementar no 108, de 29 de maio de 2001a. Dispõe sobre a relação entre a União, os Estados, o Distrito Federal e os Municípios, suas autarquias, fundações, sociedades de economia mista e outras entidades públicas e suas respectivas entidades fechadas de previdência complementar, e dá outras providências. Diário Oficial da União, Brasília, DF, 30 mai. 2001.

BRASIL. Lei Complementar ㄲo 109, de 29 de maio de 2001b. Dispõe sobre o Regime de Previdência Complementar e dá outras providências. Diário Oficial da União, Brasília, DF, 30 mai. 2001.

BRASIL. Medida Provisória ำ 919, de 1으 de fevereiro de 2020. Dispõe sobre o valor do salário-mínimo a vigorar a partir de $1^{\circ}$ de fevereiro de 2020. Diário Oficial da União, Brasília, DF, 31 jan. 2020.

CASTRO, C. A. P. de.; LAZZARI, J. B. Manual de Direito Previdenciário. $18^{a}$ ed. rev. atual. e ampl. Rio de Janeiro: Forense, 2015.

Manual de Direito Previdenciário. $21^{\underline{a}}$ ed. rev. atual. e ampl. Rio de Janeiro: Forense, 2018.

CERBASI, Gustavo. Adeus aposentadoria. Rio de janeiro: Sextante, 2014.

COMISSÃO DE VALORES IMOBILIÁRIOS. TOP: Planejamento Financeiro Pessoal. Rio de Janeiro, 2019. Disponível em: https://www.investidor.gov.br/portaldoinvestidor/export/sites/portaldoinvestidor/public acao/Livro/livro_TOP_planejamento_financeiro_pessoal.pdf. Acesso em: 27 mai. 2020.

DIEESE, Departamento Intersindical de Estatística e Estudos Socioeconômicos. Nota Técnica $\quad$ no $201 . \quad$ Disponível em: 
https://www.dieese.org.br/notatecnica/2019/notaTec201SalarioMinimo.pdf.

Acesso em: 01 jun. 2020.

FACHIN, O. Fundamentos de metodologia. 4. ed. São Paulo: Saraiva, 2003.

FRANÇA, Eveline Gomes de Oliveira. A Previdência Social Brasileira e a necessidade de Planejamento Financeiro pessoal como Estratégia para Complementação de Renda. 2020. Monografia (Especialização em Finanças) Instituto de Matemática e Estatística, Universidade Federal Fluminense, Rio de Janeiro, 2020.

GARCIA, Andréia Cristina Dias; KLOECKNER, Gilberto de Oliveira. Planejamento Financeiro Pessoal: Um estudo sobre a Renda Pós-Aposentadoria. Contexto Revista do Núcleo de Estudos e Pesquisas em Contabilidade - ISSN 2175-8751, Porto Alegre, v. 8, n. 5, p.1-23, 01 jul. 2005. Quadrimestral. Disponível em: https://seer.ufrgs.br/ConTexto/issue/view/870. Acesso em: 25 jan. 2020.

GIL AC. Métodos e técnicas de pesquisa social. 6. ed. São Paulo: Atlas; 2008; 72 p.

GITMAN, Lawrence J. Princípios de administração financeira. 12. ed. São Paulo: Pearson, 2010.

HORVARTH JR., M. Direito previdenciário. 10ª ed. rev. e ampl. São Paulo: Quartier Latin, 2014.

IBRAHIM, F. Z. Curso de direito previdenciário. $21^{\underline{a}} \mathrm{ed}$. rev. ampl. e atual. Rio de Janeiro: Impetus, 2015.

INFOMONEY, 2020. Fundos de Investimento: um guia completo para aprender a investir. Disponível em: https://www.infomoney.com.br/guias/fundos-deinvestimento/. Acesso em: 27 mai. 2020. 
INVESTIMENTOS E NOTÍCIAS, 2018. Como funciona a caderneta de poupança. Disponível em: https://www.investimentosenoticias.com.br/poupanca/caderneta-depoupanca-como-funciona. Acesso em: 16 mai. 2020.

MADUREIRA, G. L. R.; MÉXAS, M. P.; DRUMOND, G. M.. Análise da Adesão à Previdência Privada como Complemento à Aposentadoria do Trabalhador Brasileiro. Sustainable Business International Journal, [s.I.], n. 65, p. 1-27, 2 jan. 2017. Pro Reitoria de Pesquisa, Pós-Graduação e Inovação - UFF. Disponível em: https://periodicos.uff.br/sbijournal/article/view/10250. Acesso em: 16 mai. 2020.

PORTAL DA PREVIDÊNCIA, 2019. Nova Previdência. O que é Previdência Complementar. Disponível em: http://www.previdencia.gov.br/aprevidencia/previdencia-complementar/o-que-previdncia-complementar/. Acesso em: 19 abr. 2020.

PORTAL PREVIC. Previdência Complementar Fechada. Disponível em: http://www.previc.gov.br/a-previdencia-complementar-fechada/sobre-o-setor. Acesso em: 18 abr. 2020.

PORTAL TESOURO TRANSPARENTE. Tesouro Direto. Disponível em: https://www.tesourotransparente.gov.br/temas/divida-publica-federal/tesouro-direto. Acesso em: 27 mai. 2020.

SILVA, Lucílio Damião da. O Planejamento Financeiro pessoal e sua utilização como ferramenta de complementação financeira em virtude da perda salarial advinda da renda previdenciária brasileira. 2020. Monografia (Especialização em Finanças) - Instituto de Matemática e Estatística, Universidade Federal Fluminense, Rio de Janeiro, 2020.

TORORADAR, 2016. Aprenda o que é e como funciona a Bolsa de Valores. O que é taxa Selic e qual o seu rendimento. Disponível em: https://www.tororadar.com.br/blog/bolsa-de-valores-como-funciona. Acesso em: 16 mai. 2020. 
Enviado: Setembro, 2020.

Aprovado: Outubro, 2020. 